\title{
CORRECTION
}

\section{Correction to: Fuzuloparib: First Approval}

\author{
Arnold Lee ${ }^{1}$
}

Published online: 10 July 2021

(c) Springer Nature Switzerland AG 2021

\section{Correction to: Drugs}

https://doi.org/10.1007/s40265-021-01541-x

Since publication online on 12 June 2021 of this AdisInsight Report on Fuzuloparib (AiRuiYi ${ }^{\circledR}$, 艾瑞臨; formerly fluzoparib), the agent was approved in China for the maintenance treatment of patients with recurrent platinum-sensitive epithelial ovarian, fallopian tube or primary peritoneal cancer who are in a complete or partial response to platinum-based chemotherapy on 22nd June 2021 [1].

\section{Reference}

1. NMPA approval website https://mp.weixin.qq.com/s/uJ0hgF 72eAzNLNUGfSuPQ. Accessed 2 July 2021.

The original article can be found online at https://doi.org/10.1007/ s40265-021-01541-x.

Arnold Lee

dru@adis.com

1 Springer Nature, Private Bag 65901, Mairangi Bay, Auckland 0754, New Zealand 